\title{
Key Geochemical Developments in the Origin of Biogeochemistry
}

\section{THOMAS BIANCHI}

University of Florida

Presenting Author: tbianchi@ufl.edu

This talk traces the early evolution of biogeochemistry in the 18-19th centuries, as related to advancements in geochemistry. In the post-phlogiston period, we see key connections between weathering, atmospheric chemistry, carbon cycling and climate change (Bischof; Tyndall, Arrhenius; and Chamberlin). In particular, Ebelmen proposes that dissolved salts and bicarbonate can be formed from the weathering of rocks as related atmospheric carbon dioxide-launching us into the modern carbon cycle. Early work in the 19th century, focused on weathering and the importance of organisms in the exchange of carbon dioxide between the rocks and the atmosphere, provided foundations for new analytical approaches. The early work by Davy on weathering and the importance of organisms in the exchange of carbon dioxide between the rocks and the atmosphere, provided the foundation for new analytical approaches by Boussingault, that allowed Dumas and Boussingault to make connections between carbon and nitrogen. All of this was strongly influenced by Lemey and Berthollet. The development of organic geochemistry via Treibs and others as a discipline, allowed for new roots to develop in the evolution of biogeochemistry through linkages between short and long-term carbon cycles. the role microbes in connecting abiotic and biotic processes begins to emerge, based largely on the existing knowledge of stoichiometry in agricultural soils and plants. Another important development comes from the work by Darwin in 1881 on vegetable mould and worms - which for the first time explored the role of multicellular organisms in soil fertility. The next important stage is establishing how microbes "fit" with what was known about the stoichiometry of soils and plants. In 1891, Winogradsky "steals the show" with his discoveries of chemolithotrophy and mechanisms of nitrification. This all leads to Vernadsky, the father of biogeochemistry, who begins the 20th century with his idea of the biosphere and continues with the noosphere, as early concerns about what we now call the "Anthropocene," continue to develop.

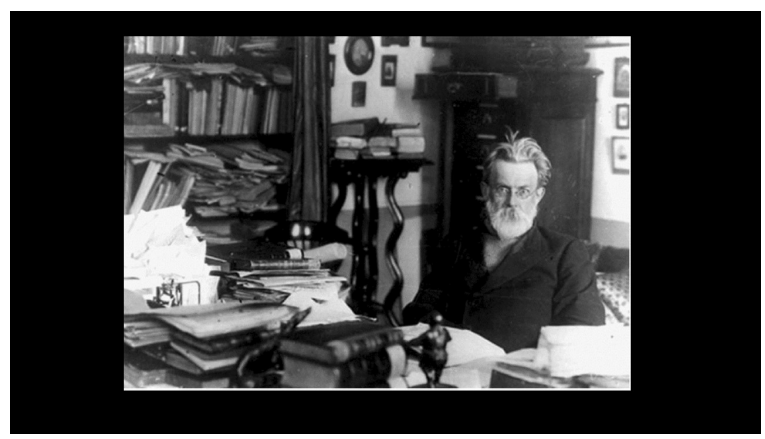

